\title{
European Forest Types and Forest Europe SFM indicators: Tools for monitoring progress on forest biodiversity conservation
}

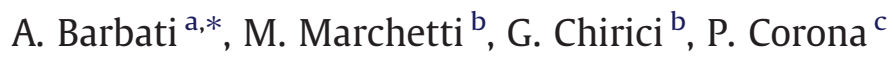 \\ ${ }^{a}$ University of Tuscia, Department for Innovation in Biological, Agro-food and Forest Systems, Viterbo, Italy \\ ${ }^{\mathrm{b}}$ University of Molise, Department of BioScience and Territory, Isernia, Italy \\ ${ }^{\mathrm{C}}$ Consiglio per la ricerca e la sperimentazione in agricoltura, Forestry Research Centre (CRA-SEL), Arezzo, Italy
}

\section{A R T I C L E I N F O}

\section{Article history:}

Available online 6 August 2013

\section{Keywords:}

European Forest Types

Sustainable forest management

Biodiversity indicators

Policy making

Monitoring

Forest Europe

\begin{abstract}
A B S T R A C T
Since 2003 the MCPFE-Forest Europe process has adopted a set of Pan-European Indicators that has become a policy instrument to monitor, evaluate and report progress towards sustainable forest management (SFM). Two new experimental tools have been introduced in the framework of the "State of Forests and Sustainable Forest Management in Europe 2011»: (i) pilot reporting by 14 classes of European Forest Types (EFTs) for a selection of quantitative SFM indicators; (ii) key parameters for monitoring progress for all quantitative indicators.

The main aim of this paper is to discuss whether reporting by EFTs of key forest biodiversity-related parameters can improve the way forest biodiversity conservation policy targets are addressed and evaluated in Europe. Accordingly, data on SFM indicators for a sample of European countries (ranging from 6 to 28 , depending on indicators) have been processed and analyzed in a pilot study using a question-driven approach, so that information from monitoring could direct policy action.

The main findings show that:

- forest area has been significantly increasing ( $>0.2 \%$ per year) in the period 2000-2010; however, annual changes in forest cover by EFTs reveal a polyedric picture at country level, in terms of gain and loss of forest habitat dominated by native and introduced tree species;

- old even aged forests (>140 yrs) are fairly consistent ( $>5 \%$ ) only in a few countries and limited to specific EFTs;

- in naturally species-poor EFTs (e.g. Boreal forest, Alpine coniferous forest, Broadleaved evergreen forest) single species stands cover from $15-100 \%$ of the total area, while in species rich EFTs (e.g. Mesophytic deciduous forest, Thermophilous deciduous forest) the maximum share of single species is in the order of $30 \%$;

- deadwood amount ranges from 9 to $26 \mathrm{~m}^{3} \mathrm{ha}^{-1}$, a value which is however far below natural reference values found in European old growth forests $\left(160 \mathrm{~m}^{3} \mathrm{ha}^{-1}\right)$.

Findings from this test demonstrate that reporting of key forest biodiversity-related parameters by EFTs enables question-driven monitoring in many ways: (i) reporting by EFTs helps to interpret the variability in the values taken by the indicators explicitly considering ecological differences between EFTs; (ii) temporal trends in forest area can be interpreted in terms of expansion or loss of forest habitats dominated by native and introduced tree species; (iii) progress in implementing biodiversity friendly strategies (e.g. increasing share of old even aged forests, promotion of multispecies stands and accumulation of deadwood) can be quantitatively evaluated against baselines.
\end{abstract}

(c) 2013 Elsevier B.V. All rights reserved.

\section{Background: biodiversity conservation and sustainable forest management in Europe}

Sustainable forest management (SFM) is widely accepted as the main goal for forest policy and practice. As demonstrated by Mc

\footnotetext{
* Corresponding author. Address: University of Tuscia, Department for Innovation in Biological, Agro-food and Forest systems, Via San Camillo de Lellis SNC, 01100 Viterbo, Italy. Tel.: +390761 357 417; fax: +390761357389.

E-mail address: barbati.sisfor@unitus.it (A. Barbati).
}

Donald and Lane (2004) there is a substantial convergence of criteria and indicators (C\&I) to measure progress towards SFM, across different regions and forest biomes of the globe: the Montreal process (MP), the Forest Europe process (FE, formerly Ministerial Conference on the Protection of Forests in Europe - MCPFE) and the International Tropical Timber Organisation (ITTO). The sustainable use of forest resources is also recognized as a focal area by the Convention on Biological Diversity (CBD, 2010a,b). 